\title{
Desafios da corporalidade na pesquisa acadêmica
}

\author{
MARIA TeREza Flores-PEREIRA \\ Universidade Federal do Rio Grande do Sul / Escola de Administração, Porto Alegre - RS, Brasil
}

EDUARDO DAVEL

Universidade Federal da Bahia / Escola de Administração, Salvador - BA, Brasil

DóRIS DORNELLES DE ALMEIDA

Universidade federal de Viçosa / Departamento de ARTes e Humanidades, ViçOSA - MG, Brasil

\begin{abstract}
Resumo
Nosso objetivo neste artigo é explorar, discutir e mapear os desafios da corporalidade (embodiment) no âmbito da metodologia de pesquisa. Consequentemente, estruturamos o artigo dentro da tradição qualitativa que se orienta pela ênfase nas atividades de interpretação, exploração e descrição. Privilegiamos duas fontes de informação: documentos existentes (pesquisas sobre corporalidade publicadas em forma de tese, dissertação, artigo, livro e capítulo de livro) e entrevistas com pesquisadoras, especialistas no tema da corporalidade. Concretizamos o resultado desta pesquisa na formulação, descrição e discussão de nove desafios decorrentes da corporalidade no âmbito da metodologia de pesquisa. Organizamos esses desafios a partir de três momentos-chave do processo metodológico: a) planejamento da pesquisa; b) interação com o campo de pesquisa; e c) análise do material empírico. Além disso, constatamos que a etnografia é a abordagem metodológica privilegiada pelos pesquisadores da corporalidade.
\end{abstract}

Palavras-chave: Metodologia de pesquisa. Corporalidade. Etnografia.

\section{The challenges of embodiment in academic research}

\begin{abstract}
The main goal of this research is to explore, discuss and map the challenges of embodiment to research methodology. Consequently, the paper follows the qualitative tradition, focusing on the activities of interpretation, exploration and description. Two sources of information are highlighted: documents (embodiment researches published as thesis, dissertation, article, book and book chapters) and interviews with scholars specialized in embodiment. The result of this research is materialized in the formulation, description and discussion of nine challenges, issued from embodiment in the context of the research methodology. These challenges are organized from three key moments in the methodological process: (a) research planning, (b) interaction with empirical material and (c) analysis of empirical material. Furthermore, ethnography appears to be the methodological approach used by scholars.
\end{abstract}

Keywords: Methodology. Embodiment. Ethnography.

\section{Retos de la corporalidad en la investigación académica}

\section{Resumen}

Nuestro objetivo en este artículo es explorar, discutir y mapear los retos de la corporalidad (embodiment) en el ámbito de la metodología de investigación. Por consiguiente, hemos estructurado el artículo dentro de la tradición cualitativa que se guía por el énfasis en las actividades de interpretación, exploración y descripción. Nos centramos en dos fuentes de información: documentos existentes (investigaciones acerca de la corporalidad publicadas como tesis, disertación, artículo, libro y capítulo de libro) y entrevistas con investigadores, expertos en el tema de la corporalidad. El resultado de esta investigación se materializa en la formulación, descripción y discusión de nueve retos resultantes de la corporalidad en el ámbito de la metodología de investigación. Estos retos se organizan a partir de tres momentos clave del proceso metodológico: a) planificación de la investigación; b) interacción con el campo de investigación; y c) análisis del material empírico. Además, se constató que la etnografía es el abordaje metodológico privilegiado por los investigadores de la corporalidad.

Palabras clave: Metodología de investigación. Corporalidad. Etnografía.

Artigo submetido em 23 abril de 2015 e aceito para publicação em 19 de dezembro de 2016.

Agradecemos o apoio do Conselho Nacional de Desenvolvimento Científico e Tecnológico (CNPq) para a realização desta pesquisa, bem como a valiosa contribuição das pesquisadoras entrevistadas.

DOI: http://dx.doi.org/10.1590/1679-395149064

Cad. EBAPE.BR, v. 15, nº 2, Artigo 1, Rio de Janeiro, Abr./Jun. 2017. 


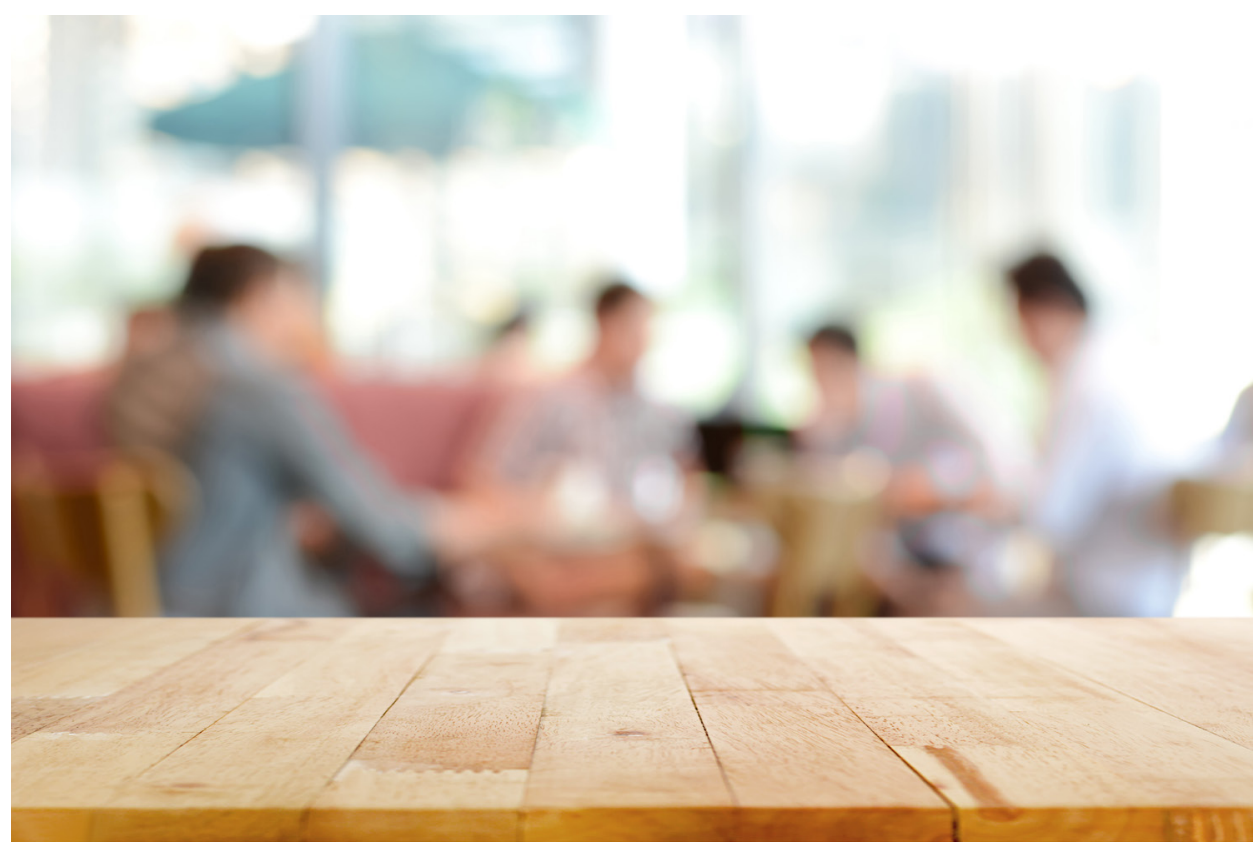

\section{INTRODUÇÃO}

A relação subjetiva entre pesquisador e pessoas pesquisadas foi discutida de várias maneiras no campo da produção acadêmica sobre metodologia de pesquisa. Por exemplo, Alvesson (2011) e Geertz (2005) falam de interação ao invés de coleta de dados, considerando o pesquisado como um parceiro durante o processo de pesquisa. Outros pesquisadores destacam a riqueza e a relevância do processo e da relação entre pesquisador e pesquisado para refinar a construção de conhecimento a respeito das questões de representação, emocionalidade, significação, discurso e linguagem (ALVESSON e SKOLDBERG, 2009; DENZIN e LINCOLN, 2000; GERGEN e GERGEN, 2000; GUBRIUM e HOLSTEIN, 1997).

No entanto, pouco se discute sobre questões metodológicas oriundas da corporalidade (embodiment), sobretudo em um momento no qual essa temática vem ganhando espaço na pauta da pesquisa acadêmica nas Ciências Sociais e inclusive no campo da Administração. Corporalidade remete à relação fundamental e inseparável que se estabelece entre corpo e mundo sócio-histórico-cultural. Do ponto de vista ontológico, rejeita-se a dicotomia corpo e mente e o paradigma mental racional-cognitivo, na medida em que a pessoa é associada ao 'seu' corpo e ao mundo que vivencia (CROSSLEY, 1995; CSORDAS, 1988; MERLEAU-PONTY, 2004; 2005; SHILLING, 2003). No entanto, poucos estudos se dedicam a discutir e a propor uma reflexão metodológica que integre a temática da corporalidade (DORNELLES DE ALMEIDA e FLORESPEREIRA, 2013).

Nosso objetivo, portanto, é explorar, discutir e mapear os desafios da corporalidade no âmbito da metodologia de pesquisa. Para tanto, o artigo foi estruturado dentro da tradição qualitativa que se orienta pela ênfase nas atividades de interpretação (PRASAD e PRASAD, 2002), exploração e descrição. Privilegiamos duas fontes de informação: documentos existentes (pesquisas sobre corporalidades publicadas em forma de tese, dissertação, artigo, livro e capítulo de livro) e entrevistas com pesquisadoras, especialistas no tema da corporalidade. A análise dessas informações nos conduziu à elaboração de 9 desafios que foram formulados, descritos e discutidos em torno de 3 momentos-chave do processo metodológico: a) planejamento da pesquisa; b) interação com o campo de pesquisa; e c) análise do material empírico.

\footnotetext{
* Fonte da imagem: Shutterstock. Disponível em: https://www.shutterstock.com/pt/pic-269015801/stock-photo-wood-table-top-with-blurred-people-incafe-as-background-can-be-used-for-montage-or-display-your-products.html?src=h30fUQWt3t7NvW2rmvqdSQ-1-3. Acesso em 26 abr. 2017.
} 


\section{A PESQUISA SOBRE CORPORALIDADE: POTENCIALIDADES}

Shilling (2003) constrói uma análise da posição e do tratamento do corpo na Sociologia, argumentando que o corpo foi, tradicionalmente, uma presença ausente. $\mathrm{O}$ termo em questão demarca a ideia de que o corpo aparece de modo implícito na Sociologia (o lado presença do termo), porém, raramente como um objeto central de estudo e pesquisa desse campo (o lado ausente do termo). A Sociologia, ao menos a clássica, preocupava-se prioritariamente com a estrutura e o funcionamento das sociedades, com a natureza da ação humana, sem atentar, entretanto, a importantes aspectos da corporalidade humana (SHILLING, 2003). São duas as áreas do conhecimento importantes para compreendermos a gradual inserção do corpo como objeto central de análise na pesquisa acadêmica: a Antropologia e a Filosofia.

Na Antropologia, a originalidade do estudo do corpo data do texto "As Técnicas do Corpo", de Mauss (2003), que argumenta que as técnicas corporais não se explicam (pelo menos não apenas) a partir de uma natureza dada, mas sim por um processo de aprendizagem e adaptação ao grupo cultural de convívio. Antropólogos sociais, estruturalistas e simbólicos seguem esse legado de Mauss (2003) ao pensar o corpo como matéria que representa as constantes trocas de significados entre o mundo 'natural' e social (SCHEPER-HUGHES e LOCK, 1987). Nesse contexto são constituídos trabalhos tradicionalmente classificados como uma Antropologia (Sociologia) do corpo (DOUGLAS, 1966; LE BRETON, 2002a; 2002b; SHILLING, 2003).

Na Filosofia, Merleau-Ponty (2004; 2005) busca (re)encontrar nosso contato direto e primitivo com o mundo que ocorre no campo da percepção, observando que este "só nos é acessível por meio do nosso corpo" (MERLEAU-PONTY, 2004, p. 18). Com isso, abre-se caminho para uma compreensão do corpo que extrapola a ideia de que o corpo é um símbolo, um espeIho da sociedade (DOUGLAS, 1966). Este se torna o ponto de partida para a construção da filosofia do embodiment e, com esta, uma área a ser denominada sociologia carnal do corpo (CROSSLEY, 1995) ou uma Sociologia (Antropologia) com o corpo (BAHNISCH, 2000; CSORDAS, 1988; CITRO, 2002; 2010; 2011; 2012; RABELO e ALVES, 2001; RABELO, MOTA e ALMEIDA, 2009; RABELO e SOUZA, 2003; VÍCTORA, 1997).

O termo embodiment ainda não foi traduzido de forma consensual em língua portuguesa, sendo empregado de modo variado pelos pesquisadores brasileiros: experiência cultural incorporada (VÍCTORA, 1997), filosofia da encarnação (RABELO e ALVES, 2001), corporeidade (CSORDAS, 2008; DORNELLES DE ALMEIDA e FLORES-PEREIRA, 2013), corpo-pessoa (FLORES-PEREIRA, 2010). Escolhemos, para os fins deste artigo, o termo corporalidade - assim como o desdobramento corporalizado(a) - por ter sido indicado pelas três pesquisadoras da área da Antropologia entrevistadas nesta pesquisa.

A corporalidade se refere a uma filosofia (CROSSLEY, 1995) que tem uma compreensão específica de corpo. Na filosofia da corporalidade, o corpo é um agente (e não um objeto) da sociedade e da cultura, ou seja, é um corpo-pessoa, pois "ela [a pessoa] 'é' o próprio corpo, um corpo pessoa, vivendo primeiramente em um mundo de prática e não da abstração" (FLORESPEREIRA, 2010, p. 422). Esse corpo-pessoa conhece o mundo de maneira prática, sem recorrer a reflexão e a intelectualização, ocasionando um know-how corporalizado (embodied) de ser no mundo (CROSSLEY, 1995). Nesse sentido, pensamentos, sentimentos, intenções, entendimentos etc. assumem formas corporalizadas e, portanto, visíveis no discurso e em outras ações culturais (CSORDAS, 1988; CROSSLEY, 1995). Por isso, uma compreensão corporalizada da vida social-organizacional humana se baseia na experiência corporal diária, no reconhecimento da noção de corpo como centro da experiência humana e no modo como os corpos são empregados, treinados, educados e usados nos espaços, inclusive de trabalho (STYHRE, 2004).

No campo da Administração, a relação entre o corpo, a corporalidade e o desenvolvimento dos Estudos Organizacionais é tratada inicialmente por Dale (2001). A autora analisa a posição e o tratamento do corpo, assim como Shilling (2003), dizendo que no nível implícito "o corpo está presente nas organizações e nos estudos organizacionais - afinal, como poderiam os trabalhadores, até mesmo gerentes, fazer qualquer coisa sem 'seus' corpos!” (DALE, 2001, p. 8). Entretanto, no nível do explícito, o corpo não é teorizado e raramente é visto como relevante para o desenvolvimento do conhecimento sobre as organizações.

Com o passar do tempo, o corpo ganha centralidade nas pesquisas da Administração, abarcando tanto uma produção de corpo que se preocupa em designar aquilo que é feito ao corpo - o corpo como um símbolo, um espelho da organização/trabalho (ECCEL, GRISCI e TONON, 2010; FLORES-PEREIRA, CAVEDON e DAVEL, 2007; HOLLIDAY e THOMPSON, 2001; MATOS, 1984; SINCLAIR, 2005; TRETHEWEY, 1999; ROSA e BRITO, 2010) - quanto aquilo que o corpo faz - uma filosofia da corporalidade no trabalho e nas organizações (BALL, 2005; BARRY e HAZEN, 1996; DALE, 2005; DALE e BURRELL, 2013; DORNELLES DE ALMEIDA, 2012; DORNELLES DE ALMEIDA e FLORES-PEREIRA, 2013; FLORES-PEREIRA, DAVEL e CAVEDON, 2008; FIGUEIREDO e IPIRANGA, 
2015; HASSARD, HOLLIDAY e WILLMOTT, 2000; HINDMARSH e PILNICK, 2007; KERFOOT e KNIGHTS, 1996; MONAGHAN, 2002; SOUZA, COSTA e PEREIRA, 2015; STYHRE, 2004).

Percebemos, ainda, que os textos que tratam da temática da corporalidade, nas Ciências Sociais e na Administração, em muitos momentos realizam uma discussão teórica sobre o tema, mas em tantas outras utilizam tal filosofia para pensar um contexto social (CITRO, 2002; 2010; 2011; 2012; CSORDAS, 1988; RABELO, MOTA e ALMEIDA, 2009; RABELO e SOUZA, 2003; VÍCTORA, 1997), organizacional (DALE, 2005; DORNELLES DE ALMEIDA, 2012; FLORES-PEREIRA, 2007; FLORES-PEREIRA, DAVEL e CAVEDON, 2008) ou de trabalho (DORNELLES DE ALMEIDA e FLORES-PEREIRA, 2013; HINDMARSH e PILNICK, 2007; MONAGHAN, 2002) a partir de uma pesquisa com um enfoque empírico. Dentre todos esses estudos que refletem e discutem a corporalidade a partir de um caso empírico, a abordagem etnográfica (ou pelo menos o uso das técnicas de observação sistemática) é predominante.

Inicialmente concebida para estudar a cultura de um ponto de vista representacional, a etnografia, então, vem sendo utilizada para estudar a corporalidade. Isso nos incita a pensar: estão sendo adotadas adaptações nesse método? Caso sim, quais adaptações são essas? Csordas (1999) fala de uma 'atitude metodológica' do pesquisador, pois tal abordagem requer atenção para a corporalidade presente em dados que advêm de textos ou de entrevistas presenciais. Dornelles de Almeida e Flores-Pereira (2013) destacam a importância de privilegiar a vivência corporal dos informantes, com o objetivo de obter uma compreensão corporalizada do material de campo. As autoras denominam tal "conjuntura metodológica" como uma "etnografia corporificada" (DORNELLES DE ALMEIDA e FLORES-PEREIRA, 2013, p. 727), entretanto, não detalham os processos de 'captura' e de análise da corporalidade em seu campo empírico.

Desse modo, desenvolver uma abordagem de pesquisa corporalizada, demonstra ser não apenas um desafio ontológico, mas também um desafio metodológico (BROWN, CROMBY, HARPER et al., 2011). Diante da inexistência de trabalhos com discussões sobre os procedimentos metodológicos para tal tipo de investigação, tornamos a seguinte proposta prioritária: Quais são os principais desafios metodológicos ao nos valer da corporalidade como dispositivo empírico para a construção do conhecimento?

\section{A PESQUISA SOBRE CORPORALIDADE: DESAFIOS}

\section{Sobre o método}

Neste estudo de tradição qualitativa, com enfoque na interpretação (PRASAD e PRASAD, 2002), exploração e descrição, privilegiamos duas fontes de informação: a) documentos existentes; e b) entrevistas semiestruturadas. Os documentos existentes se referem a pesquisas empíricas que trabalham com a filosofia da corporalidade e que estão publicadas em forma de tese, dissertação, livro e capítulo e artigos em revistas acadêmicas. As entrevistas semiestruturadas ocorreram com seis pesquisadoras com experiência teórico-empírica no tema da corporalidade, sendo estas autoras das pesquisas utilizadas na fonte de informação documental.

No campo das Ciências Sociais, entrevistamos três pesquisadoras da Antropologia que estudam questões de corporalidade desde meados da década de 1990, todas professoras doutoras. Utilizaremos o título Pesq. e uma letra maiúscula como nomenclatura para identificar as entrevistadas, sendo elas: a Pesq.C, a Pesq.M e a Pesq.S. A Pesq.C é professora do Departamento de Antropologia e do Programa de Pós-Graduação em Antropologia Social da Universidade Federal do Rio Grande do Sul (UFRGS); a Pesq.M é professora do Departamento de Sociologia e do Programa de Pós-Graduação em Ciências Sociais da Universidade Federal da Bahia (UFBA); e a Pesq.S é professora da Facultad de Filosofía y Letras da Universidad de Buenos Aires (UBA).

No campo das Ciências Sociais Aplicadas entrevistamos três pesquisadoras da Administração, que estudam a corporalidade desde 1995, 2005 e 2012, respectivamente. A Pesq.K, doutora, leciona no Department of Organisation, Work and Technology da Lancaster University. A Pesq.T, também doutora, é professora do Departamento de Ciências Administrativas da UFRGS. A Pesq.D, mestre em Administração, é professora do Curso de Dança da Universidade Federal de Viçosa (UFV). As entrevistadas 
Pesq.S e Pesq.D, por coincidência e não intencionalidade, apresentam além da experiência acadêmica uma relação importante com a área das Artes a partir da Dança.

Para aprofundar a experiência de tais pesquisadoras com o campo da corporalidade e, mais especificamente, com suas escolhas metodológicas, optamos por construir um roteiro de entrevista personalizado. Para cada pesquisadora entrevistada lemos pelo menos 1 (e no máximo 4) textos por elas publicados. A partir dessas leituras, construímos um roteiro de perguntas que buscavam incitar uma reflexão de cada pesquisadora sobre seu próprio processo metodológico de 'encontrar' a corporalidade em campo. Realizando uma análise entremeada das 6 entrevistas transcritas e dos 12 textos publicados, buscamos explorar, discutir e mapear os desafios enfrentados pelo pesquisador do tema da corporalidade. Nosso processo de análise foi guiado por 3 momentos-chave: a) planejamento da pesquisa; b) interação com o material empírico; e c) análise do material empírico.

\section{PLANEJAMENTO DA PESQUISA: COMPREENDENDO A RELAÇÃO DE PESQUISA}

O que se torna distintivo no momento-chave planejamento da pesquisa, quando falamos de um estudo sobre corporalidades, é a necessidade de compreender a relação de pesquisa. A partir da fala das pesquisadoras entrevistadas, entendemos que tal compreensão passa por um processo no qual os antecedentes teórico-empíricos e a leitura e o entendimento da epistemologia da corporalidade são fases importantes. Os antecedentes teórico-empíricos referem-se ao histórico de estudo e às trajetórias individuais de pesquisa e de vida das pesquisadoras que de alguma maneira construíram uma conexão com a filosofia da corporalidade.

No campo da Antropologia, a Pesq.C traz como antecedente sua dissertação de mestrado, na qual já trabalhava com a questão do corpo, porém, tratando "as representações de um certo tipo de corpo, um tipo de corpo estático". Foi no início da década de 1990, quando foi fazer seu doutorado na Inglaterra, que a Pesq.C começou a se familiarizar com a filosofia da corporalidade, a qual até aquele momento não tinha difusão no Brasil. A Pesq.M fala que construiu sua trajetória de pesquisa no campo da Antropologia da Religião e da Saúde, sempre muito preocupada com a questão da prática e da vida cotidiana, sendo que foi nesse contexto que o corpo acabou se tornando uma temática importante para ela, "por que era [o corpo] a questão que ia aparecendo quando a gente reflete sobre a prática". Já a Pesq.S crê que a escolha das temáticas de pesquisa é uma dialética entre o contexto histórico e a memória subjetiva do pesquisador. A pesquisadora fala de uma vivência em dois 'mundos' por um período de sua vida: o mundo da dança e o mundo acadêmico. O mundo da dança, que era seu trabalho cotidiano, era todo por meio do corpo, enquanto a formação acadêmica implicava um corpo "totalmente quieto, um corpo bem mais passivo". Chegou um momento em que, quando teria que escolher sobre o que pesquisar para completar sua formação acadêmica, a Pesq.S se propôs a fazer algo que tivesse relação com o corpo, o movimento e a dança.

No campo da Administração, a Pesq.K se descreve como uma construtora de teoria, mas, talvez por ter sido uma praticante antes de ser uma acadêmica, ela busca construir uma teoria que esteja conectada à experiência organizacional vivida. É nessa conjunção que a Pesq.K contextualiza a escrita de sua tese sobre corpo e corporalidade nos Estudos Organizacionais. A Pesq.T diz ter conhecido os estudos de corpo e corporalidade no início de seu doutorado, quando cursou a disciplina Antropologia do Corpo e da Saúde. No decorrer dessa disciplina, a Pesq.T diz ter atentado para a possibilidade de construir sua tese utilizando o material teórico dessa disciplina antropológica. Entretanto, analisa que foi apenas na fase de escrita sobre seu material empírico que a filosofia da corporalidade se apresenta de maneira mais intensa na sua pesquisa. A Pesq.D, por sua vez, fala sobre seu desejo de pesquisar a relação bailarino/companhia de dança ligando isso ao fato dela própria ser bailarina. Analisa que a escolha da filosofia da corporalidade ocorreu em função desta "permitir que fossem observados os corpos nas suas relações e interações com os outros corpos e seus ambientes de trabalho".

Uma segunda fase desse processo de compreensão da relação de pesquisa se refere à leitura e ao entendimento da filosofia da corporalidade, fomentando um entendimento das relações que se estabelecem entre pessoa e mundo a partir de uma ontologia e uma epistemologia menos dicotômica, mais fluida e entrelaçada. Sobre essa questão, a Pesq.C considera primordial o pesquisador se embasar teoricamente, pois os dados, se não houver uma teoria que permita sua análise, "são puramente 
dados, eles não falam por si, a gente faz eles falarem conforme as perguntas que a gente está fazendo para eles". Para falar sobre esses dados a partir da filosofia da corporalidade, a Pesq.C começou a ler sobre Fenomenologia, contando com o apoio direto de seu orientador de doutorado. Foi a partir dessa compreensão que a Pesq.C conseguiu retornar a um dado de campo, chamado 'emicamente' como a mãe do corpo, enxergando, então, neste, uma relação corporalizada. A Pesq.M, um pouco diferente, chega no material teórico da corporalidade pelos estudos das práticas. Nesse sentido, a pesquisadora diz ter passado por Alfred Schultz, Merleau-Ponty para tratar de seus temas da Antropologia da Religião não como discurso, mas como uma prática corporal. Com uma proposta de unir os dois mundos nos quais vivia a partir de seu trabalho acadêmico final, a Pesq.S começa a ter acesso aos primeiros textos de Thomas Csordas, Merleau Ponty, Michael Jackson, Margareth Lock e passa, então, a construir um marco teórico e metodológico para abordar a corporalidade em suas pesquisas.

Na área da Administração, a Pesq.K não detalha seu caminho teórico dos estudos de corpo, mas fala que sua aproximação com o tema do corpo ocorre a partir da leitura de um texto clássico na área de Estudos Organizacionais - "Sex and organizational analysis" (BURRELL, 1984) - a partir do qual percebeu que a corporalidade humana era uma presença ausente em grande parte da Teoria Organizacional. A Pesq.T acessou o material sobre corpo pela literatura da Antropologia do Corpo para, em um segundo momento, dedicar-se aos estudos de uma filosofia da corporalidade. Tal estudo ocorreu pela leitura de Thomas Csordas, Merleau-Ponty, assim como diversos outros autores, inclusive textos das pesquisadoras C, M e K. Apesar de desejar pensar sua própria pesquisa sobre um ritual organizacional a partir da perspectiva da corporalidade, a Pesq.T comenta que, para ser capaz de adotar a postura da corporalidade diante de seu material empírico, tomou duas atitudes: 1) leu por diversas vezes uma etnografia de Csordas sobre um ritual religioso, pensando sobre o conteúdo da teoria de corporalidade presente na análise daquele ritual; 2) solicitou auxílio para alguém com maior conhecimento da Fenomenologia, com o intuito de 'decifrar' tal campo de estudos. Já a Pesq.D destaca sua leitura de diversos autores como Thomas Csordas e Merleau Ponty, mas também o fato de ter estendido suas buscas a textos que analisassem a corporalidade no campo da dança e, especialmente, das companhias de dança, que eram seu foco de pesquisa no mestrado.

A análise dos processos referentes aos antecedentes teórico-empíricos e à leitura e entendimento da filosofia da corporalidade possibilita refletir sobre três desafios que podem se apresentar no planejamento da pesquisa:

- Desafio 1 - A aproximação em relação à filosofia da corporalidade: Constitui-se a partir do desconhecimento do desenvolvimento teórico da filosofia da corporalidade. Esse desconhecimento ocorre no campo de pesquisas da Administração brasileira pela falta de publicações, em português, que adotem essa abordagem (DORNELLES DE ALMEIDA e FLORES-PEREIRA, 2013), mas também nas Ciências Sociais e na Filosofia, uma vez que compõe um campo de estudos ainda recente e não hegemônico.

- Desafio 2 -A compreensão teórica da filosofia da corporalidade: Diz respeito à necessidade de um esforço 'a mais' para compreender a filosofia da corporalidade, pois esta se constitui a partir de uma diferente ontologia acerca do que é ser humano e da relação deste com o mundo. Desse modo, não se refere 'apenas' à leitura de uma teoria, mas sim à compreensão - preferencialmente praticada e corporalizada - de outra forma de relacionar-se consigo, com os outros e com o mundo.

- Desafio 3-A compreensão de que a filosofia da corporalidade poderá trazer diferentes 'luzes' para a análise do material de campo: Alude à aplicação da filosofia da corporalidade a determinado campo de pesquisa. Perceber a corporalidade nos dados de campo significa compreender como a corporalidade é implicada na vida cotidiana. Para isso, é essencial a compreensão teórica da filosofia da corporalidade, mas também se torna necessária uma 'atitude metodológica' do pesquisador (CSORDAS, 1999). É essa tal 'atitude metodológica' que seguimos investigando neste texto.

\section{INTERAÇÃO COM CAMPO DE PESQUISA: VIVENCIANDO A RELAÇÃO DE PESQUISA}

O momento-chave de interação com o campo de pesquisa compõe outra fase importante da pesquisa teórico-empírica sobre corporalidades. As experiências de pesquisa das entrevistadas apresentam a necessidade do pesquisador compreender $a$ relevância da familiaridade do pesquisador com o campo empírico e o valor de desenvolver uma sensibilidade no uso das técnicas etnográficas. 
O tema da familiaridade com o campo empírico para a construção de uma compreensão corporal apareceu de diferentes maneiras nas entrevistas das pesquisadoras. Sobre a familiaridade, a Pesq.T faz uma breve comparação entre suas duas experiências etnográficas - a primeira em uma livraria de shopping center e a segunda em uma cozinha de restaurante. Sobre seu segundo trabalho etnográfico, a cozinha de restaurante, embora a Pesq.T estivesse mais madura em relação ao material teórico da corporalidade e tenha ido a campo especialmente para estudar a corporalidade, ela diz que viu

[...] menos embodiment na cozinha do que na livraria [...] isso não quer absolutamente dizer que tinha menos embodiment na cozinha do que na livraria. Embodiment não diz respeito a uma questão quantitativa/mensurável, significa dizer que eu não consegui/quis denominar muitas práticas embodied nessa cozinha de restaurante.

Ela se questiona: "será que essa dificuldade surgiu da minha pouca familiaridade com o ambiente da cozinha? Eu consegui ver mais embodiment na livraria devido à minha familiaridade com esse éthos/pathos?". Também comenta sobre sua dificuldade de encontrar a corporalidade em seu material empírico da livraria, pois a cultura - corporativa, social - que estava sendo vivenciada por seus pesquisados se materializava a partir de movimentos e ações corporais que eram "tão naturalizados [por mim, inclusive, é claro] que se tornavam de difícil percepção/análise".

Essa dificuldade de analisar um campo de pesquisa familiar também é colocada pela Pesq.S, a qual entende que é mais difícil desnaturalizar o familiar do que tornar familiar o diferente. Para exemplificar isso, a pesquisadora lembra de sua pesquisa com os Tobas - um grupo indígena do norte da Argentina - sobre a corporalidade no cotidiano, dizendo esta pesquisa ter sido algo "muito simples". Tal simplicidade decorre, em sua análise, da grande diferença entre a corporalidade dos Tobas e a sua, analisando que nesse caso o trabalho do antropólogo é tratar de entender (não valorar) o sentido, colocar no contexto os hábitos corporais. No caso de outra pesquisa sobre shows de uma banda de rock argentina - Bersuit Vergarabat -, a Pesq.S analisa que, se por um lado havia familiaridade (ambiente urbano), por outro, também havia certa distância (questão de geração). A pesquisadora relembra que na pesquisa sobre a banda de rock questões de gênero e relações de poder não foram percebidas por ela em uma primeira análise. Nesse sentido, pondera que estudar o familiar pode incitar o pesquisador a crer no discurso nativo, sem maiores suspeitas, por que é algo que o próprio pesquisador pode ter internalizado.

A Pesq.M relaciona diretamente familiaridade com possibilidade de melhor compreensão do campo. Ela afirma: "se você ainda não está familiarizado com aquela prática, você é capaz de ver muito pouco acerca dela. Quanto mais a gente é familiarizado com a prática, mais a gente vê acerca dessa prática". A Pesq.D exemplifica essa argumentação ao falar sobre a importância de sua familiaridade com o campo do ballet para a compreensão da corporalidade dos bailarinos de companhias de dança. Ela explica que sua vivência como bailarina a auxiliou a traçar um paralelo do campo com experiências que já tinha vivido, no caso, a de perceber na dança dos observados questões corporalizadas, como o dançar com a alma, as posturas eretas, as sensações de dor, prazer, toques, energias e presença. A pesquisadora entende, ainda, que o fato de ter tido treinamentos e vivências corporais muito semelhantes às dos pesquisados, torna-se um uma vantagem metodológica, pois é capaz de perceber mais, de perder menos tempo diferenciando técnicas ou interpretação "que são como um como um vocabulário próprio". Pondera, todavia, que

[...] ao mesmo tempo tive que tentar ter um distanciamento e não ter as percepções a priori, ou seja, tentei ir a campo despida de meus conhecimentos e predileções e tentar ver coisas que mesmo nestes 19 anos não havia percebido.

A Pesq.C, por outro lado, avalia que a questão da familiaridade com o 'objeto' de pesquisa não é algo tão simples. No caso, ela fala sobre sua pesquisa com mulheres de camadas populares que há pouco haviam ganhado neném, sendo que ela também já havia passado por essa experiência da maternidade. As pesquisadas falavam de "uma certa 'mãe do corpo"' e ficavam surpresas ao perceber a falta de conhecimento da Pesq.C sobre a mãe do corpo, perguntando: se ela era mãe, como ela nunca havia sentido a mãe do corpo? A pesquisadora comenta que era mãe no momento da pesquisa e aos poucos percebeu que para sentir a mãe do corpo não era necessário apenas ser mãe biológica, mas sim ser mãe biológica em uma camada social diferente da sua de origem. 
Dentro da vivência do campo empírico no qual se busca considerar as corporalidades, a sensibilidade no uso das técnicas de pesquisa é um aprendizado importante para o pesquisador. Três ideias emergem da análise das entrevistas com as pesquisadoras: 1) a observação sensível; 2) o questionamento experiencial; e 3) a descrição imediata. A observação sensíve/ visa a compreender o campo de pesquisa como um tempo/espaço de vivência e não apenas um tempo/espaço de coleta de dados/ informações, pois "os significados sociais, eles estão aí sendo tecidos corporalmente na nossa experiência corporal" (Pesq.M). Nesse sentido, o método etnográfico vem demonstrando ser privilegiado, uma vez que implica uma ampla convivência do pesquisador com o campo de pesquisa. Não desconsiderando a importância e a possibilidade de 'encontrar' a corporalidade a partir da fala êmica, a Pesq.S comenta que sempre trabalhou em uma perspectiva de observação participante e que, mesmo utilizando o recurso metodológico das entrevistas, entende que "as coisas mais ricas surgiam do cotidiano, de estar ali".

Uma experiência de observação sensível é relatada pela Pesq.T, durante sua etnografia de um ritual organizacional. Ao observar e participar do ritual, ela vivenciava a alegria, a criatividade, a ironia, a raiva. Ela se entregou corporalmente ao ritual e isso foi fundamental para que realizasse uma observação ultrapassando a simples descrição visual de algo. A pesquisadora relata que esse tipo de observação ajudou-a a perceber melhor quem eram as pessoas envolvidas na pesquisa de campo, pois vivenciara a realidade destas a partir de sensações compartilhadas. Essa experiência intensa da Pesq.T corrobora uma ideia importante trazida pela Pesq.M sobre a pesquisa, em especial sobre a 'técnica' da observação participante. A pesquisadora fala da necessidade do pesquisador se deixar afetar em um campo etnográfico, pois tem

[...] um momento na pesquisa em que a gente se arrisca, que a gente não consegue sustentar essa posição de observador, que a gente se deixa afetar pelo campo [...] por que se eu não sou afetado pelo campo, eu não vou poder dizer muita coisa a respeito do mundo que os outros estão vivendo.

Essa exposição do pesquisador à vivência do campo é analisado pela Pesq.M como algo que cria "uma porta para compreender a vivência do outro". A Pesq.S segue nessa mesma linha: considera fundamental entrar na dinâmica do grupo que se pesquisa, fazer as mesmas coisas não apenas pela experiência de fazer o mesmo que os outros fazem, mas também porque essa vivência abre o pesquisador para outros tipos de questionamento.

Ainda sobre a ideia da observação sensível, a Pesq.M traz uma dica metodológica, que é a possibilidade de focarmos os modos como as cenas sociais se (re)organizam. Para ela,

[...] as relações com o espaço e as coisas são fundamentais na constituição e na transformação dos corpos, uma vez que "cada uma dessas formas [espaço e coisas] pede um certo tipo de corpo" e "este corpo vai se fazendo, respondendo a estas solicitações".

Essa dica se assemelha a algumas análises empíricas da Pesq.K, a qual trabalha com as temáticas da corporalidade, do espaço e da materialidade, de maneira entrelaçada. A pesquisa da Pesq.K busca analisar a relação entre mudanças arquitetônicas do prédio onde funciona determinada organização e as relações corporais constituídas pelos empregados para essa nova configuração arquitetônica. A Pesq.K percebeu, por exemplo, uma linguagem de sinais (corporalidade) criada e usada entre os funcionários como algo que se tornou possível a partir de uma estrutura arquitetônica totalmente aberta e de vidro transparente (espacialidade e materialidade).

Mesmo que a observação sensível, em muitos momentos, seja uma técnica privilegiada, quando falamos de pesquisas sobre corporalidade, a questão da fala êmica - seja ela proferida no campo cotidiano ou em forma de entrevistas - também é fonte de informação sobre a corporalidade. $O$ modo de compreendermos a corporalidade a partir da fala êmica, entretanto, parece ser diferente de uma pesquisa que busca os significados das coisas. Por exemplo, ao invés de perguntarmos como uma pessoa define, entende ou pensa determinada situação, buscamos conhecer o sentimento delas, como elas 'experienciam' determinada situação. Essa análise compõe uma segunda ideia que emerge das entrevistas sobre a sensibilidade no uso das técnicas de pesquisa que é a técnica do questionamento experiencial. Sobre a necessidade de realizar um questionamento experiencial quando se faz uma pesquisa sobre corporalidades, temos mais uma vez a pesquisa com mães de camadas populares da Pesq.C. Em seu texto, a pesquisadora reproduz o percurso teórico-metodológico que a fez compreender o que seria o dado de campo a mãe do corpo para suas informantes. No princípio, quando ainda não havia sido exposta à literatura sobre corporalidade, a pesquisadora disse ter construído perguntas que buscassem uma reflexão das pesquisadas, como: "O que é $a$ 
mãe do corpo?" ou "O que tu pensas sobre isso?", tendo obtido respostas como: "Eu não penso, eu sinto". Foi na medida em que começou a entender sobre a filosofia da corporalidade. Percebe que a mãe do corpo não está no nível do pensar, mas no nível do sentir, do experimentar. Ou seja, um modo diferente de questionar seria necessário.

A Pesq.M defende a ideia de que existem formas de linguagem que são muito próximas da experiência vivida, sendo a narrativa uma delas. Nesse sentido, se o objetivo da pesquisa é considerar a corporalidade, então, deve-se evitar perguntas do tipo "o que você entende por mau-olhado?", por exemplo, podendo substituir esse tipo de pergunta pela demanda de uma narrativa, como "conte uma história sobre mau-olhado". Ao passar para a tática da narrativa, analisa a Pesq.M, "você está pedindo que a pessoa compartilhe uma experiência com você". A Pesq.S também aborda essa questão do questionamento experiencial, o qual se refere a uma construção de perguntas diretas sobre as sensações:

[...] por que se formos colocar uma pergunta, como: O que é o gozo? O que é isso? O que pensa que é? A primeira resposta a isso será "não podemos explicar". Então, tem que mudar, mudar de uma maneira que se pergunte mais: O que sentes? Como foram as sensações? O que te ocorreu? Mudar nossos termos para algo mais experiencial. [...] $O$ que sentes quando te acontece isso? $O$ que sentes corporalmente? Como te sentes depois de tal coisa? Me parece que isso ajuda muito.

Analisando as entrevistas com essas pesquisadoras, emerge, ainda, no processo de desenvolver uma sensibilidade no uso das técnicas, a ideia da descrição imediata. Trata-se de uma descrição que não foca o detalhamento da significação das situações, mas a descrição do que está acontecendo, tentando captar seu caráter imediato. A Pesq.M destaca que é preciso se dedicar muito à descrição. Para a pesquisadora, a agenda principal da pesquisa sobre corporalidades deve estar centrada na convivência e na possibilidade de escrever sobre tais eventos (de convivência). Ou seja, o pesquisador deve deixar de se preocupar com o significado das coisas, passando a se atentar "para o que tá acontecendo", ou então "para a maneira pela qual as pessoas estão descrevendo aquilo que elas estão fazendo".

A Pesq.D fala que seu trabalho de campo foi muito intenso e percebemos que tal intensidade não se refere apenas à observação sensível, mas ao seu esforço de construir uma descrição imediata dessa observação. Ela conta que decidiu levar o diário de campo ${ }^{1}$ a campo para poder:

[...] anotar todos os apontamentos, percepções no momento em que elas ocorriam, na sala, ficava sentada com meu papel e caneta e escrevia tudo que observava e considerava importante ou não [...] obcecada pelos detalhes e sugando tudo que via, pois não sabia ao certo qual daquelas informações me seriam úteis na análise, e de repente alguma coisa que eu considerasse comum e não anotasse poderia ser a mais útil depois.

Essa anotação de tudo se refere a um enfoque múltiplo que a Pesq.D adotou em relação à questão da corporalidade em seu campo de pesquisa. Sua descrição passou por movimentos e poses tradicionais do ballet (postura ereta, olhar altivo), mas também por movimentos e poses de resistência (postura curvada, caretas). Apontou algumas questões sensoriais (cheiros, toques) e alguns processos corporais (respiração, choros, alimentação). Relacionou o corpo à materialidade (relação com o espelho), à espacialidade (distribuição dos bailarinos no corpo de baile) e à temporalidade (jornadas de trabalho exaustivas). Além disso, buscou descrever questões corporativas relacionadas à companhia e ao local de trabalho (organograma, equipe, organização espacial).

As técnicas para elaborar essa descrição imediata podem variar. Pesq.D falou sobre levar o diário de campo a campo. Já a Pesq.T comenta sobre trabalhar no campo apenas com um pequeno bloco de notas e gostar de escrever seu diário de campo em um dia seguinte, a mão, pois, para ela, "a possibilidade de mudar a letra, desenhar, facilitava a transposição das sensações do campo para o papel". Métodos tradicionais, como a agenda e a gravação de entrevistas, as fotografias, a filmagem também foram citados pelas pesquisadoras como passíveis de compor essa descrição imediata do campo. Especialmente sobre vídeos e fotos, a Pesq.D comentou que tais dispositivos a "auxiliaram a relembrar alguns momentos, fortificar algumas sensações sobre os bailarinos e refletir sobre a vivência em campo". A Pesq.S discorre um pouco mais sobre o uso de

\footnotetext{
${ }^{1}$ Diário de campo é um instrumento de pesquisa com muita tradição na pesquisa etnográfica, cujo objetivo é a anotação (descrição) dos acontecimentos do campo de pesquisa, permitindo assim uma posterior análise desse material empírico.
} 
recursos de vídeo e desenhos feitos por ela. Sobre o vídeo, ela analisa que pode ser útil na medida em que não conseguimos anotar tudo e que este ajuda, em um momento posterior ao campo, a relembrar questões do corpo. Ela também comenta que usou muito do recurso do desenho "para conhecer os movimentos e as coreografias, usar o corpo para falar de si". Ela lembra, entretanto, que sempre é um desafio, depois na análise, dar conta desse material.

Quando se fala da fase empírica de uma pesquisa, a ideia de ir a campo está tradicionalmente orientada à atividade de coletar dados ou informações. Pressupõe-se um maior afastamento entre pesquisador e pesquisado, validando a dicotomia pessoa e objeto, sustentada pela modernidade ocidental. Quando se fala de uma pesquisa etnográfica, um pouco dessa ideia de coleta é substituída por uma compreensão sobre uma interação com o campo (GEERTZ, 2005) uma vez que o pesquisador não é apenas alguém inserido no campo para coletar o dado, pois o dado se apresenta muitas vezes a partir desse processo de interação pesquisador-pesquisado. Uma pesquisa que usa o método etnográfico para estudar a corporalidade torna ainda mais extrema a necessidade da quebra dessa dicotomia, uma vez que é uma filosofia que parte de uma compreensão não dividida do mundo.

A pesquisa empírica que se propõe a trabalhar o tema da corporalidade deve ser compreendida como algo que é mais do que um simples meio de pesquisa, uma técnica. Ela é a instância na qual a experiência humana está acontecendo e sendo progressivamente experimentada pelo pesquisador e pelo pesquisado. Dentro desse contexto, pelo menos quatro desafios se apresentam ao pesquisador no momento-chave interação com o campo da pesquisa:

- Desafio 4 - 0 entendimento da proximidade do pesquisador com o campo empírico (familiaridade ou distanciamento): Refere-se à importância do pesquisador refletir sobre sua proximidade com o campo empírico, de forma a compreender o tipo de esforço que deverá fazer no sentido de buscar compreender as corporalidades. Essa proximidade pode ocorrer a partir de uma familiaridade ou de um estranhamento, mas mesmo dentro dessas duas possibilidades existem nuances. Por exemplo, pode haver um tipo de familiaridade que facilite a interação do pesquisador com o campo (o caso do campo do ballet da Pesq.D), pode ser uma familiaridade 'parcial', que não chega a auxiliar na compreensão do campo (o caso da mãe do corpo da Pesq.C) ou uma familiaridade que leva a uma certa 'cegueira' em relação a corporalidade do campo (o caso do ritual organizacional da Pesq.T). No caso do estranhamento, essas nuances também podem estar presentes, passando por situações nas quais o campo é tão estranho a ponto de se tornar muito fácil a percepção da corporalidade (os indígenas Tobas da Pesq.S) ou a ponto de dificultar a percepção da corporalidade em campo (a pesquisa na cozinha de restaurante da Pesq.T).

- Desafio 5-O aprendizado prático sobre o que é realizar uma observação sensível: Remete à compreensão de que a observação sensível deve se encarregar de compreender o campo de pesquisa como o 'aglomerado' das interações advindas dos sujeitos pesquisador, pesquisado e suas corporalidades, e da relação desta com as dimensões da espacialidade, da materialidade e da temporalidade.

- Desafio 6 - O aprendizado prático sobre como construir um questionamento experiencial: Refere-se ao aprendizado do pesquisador de construir formas de questionamento ao pesquisado que captem suas experiências, suas sensações em relação a esse mundo que ele vivencia (e não apenas reflete sobre).

- Desafio 7 - 0 aprendizado prático sobre como realizar uma descrição imediata: Empreende sobre o exercício do pesquisador de construir uma descrição imediata do campo de pesquisa, uma descrição que detalhe os eventos de convivência e que descreva de que maneira os corpos (pessoas) corporificam (embody) tais eventos. A partir desse tipo de descrição conseguimos chegar, por um processo de análise, na relação imediata (corporalizada) que as pessoas (pesquisados, no caso) constituem com o mundo.

\section{ANÁLISE DO MATERIAL EMPÍRICO: REFLETINDO SOBRE OS RESULTADOS DA RELAÇÃO DE PESQUISA}

O momento-chave Análise do material empírico é aquele no qual o pesquisador produz os resultados da pesquisa levando em consideração a corporalidade do campo de pesquisa. O que se torna distintivo nesse momento de pesquisa, quando falamos 
de um estudo sobre corporalidades, é a necessidade de transformar uma experiência corporal que ocorre em um momento anterior ao da reflexão (pré-reflexiva) em um texto reflexivo sobre as corporalidades. As entrevistas das pesquisadoras nos levaram a compreender que esse processo demanda uma reconstrução e uma recontextualização das corporalidades.

A reconstrução das corporalidades se refere à atividade do pesquisador de apontar e analisar as corporalidades vivenciadas no campo empírico construindo, assim, um conhecimento sobre as corporalidades que dê conta de compor um texto acadêmico. Falamos de reconstrução, pois a construção das corporalidades ocorreu em momento anterior, na vivência com o campo empírico. Resta a esse momento de pesquisa a reflexão sobre o material empírico obtido com as técnicas sensíveis de pesquisa ou até um retorno à memória sensível do pesquisador, com o intuito de reconstruir, na forma de texto científico, as corporalidades do sujeito de pesquisa.

Pelas entrevistas com as pesquisadoras, podemos dizer que o processo de reconstrução das corporalidades ocorre a partir de uma imbricada relação entre material teórico e material empírico. A Pesq.C comenta essa relação quando fala da diferença entre a mãe do corpo como um dado etnográfico e da mãe do corpo como um processo de corporificação: “a mãe do corpo surgiu para mim [...] como um dado etnográfico. Mas, também como um problema. Eu acabei pensando daquela maneira, como um processo de corporificação e como uma teoria". A Pesq.T relata uma situação de pesquisa que também exemplifica essa relação imbricada entre teoria e empírico no processo de reflexão final sobre a pesquisa de campo. Percebe-se correndo como os funcionários e vai analisando isso como uma prática cultural 'embodied'. Ela atribui essa "possibilidade de denominação daquela prática observada empiricamente como algo embodied, como algo advindo de maiores leituras e de um amadurecimento sobre a teoria do embodiment".

A reconstrução das corporalidades demanda, ainda, uma literatura de apoio que trabalhe a filosofia da corporalidade a partir de temas específicos. A pesquisa do ritual organizacional, da Pesq.T, por exemplo, utiliza estudos sobre rituais que buscassem compreender os rituais não como uma função ou um símbolo, mas como uma experiência corporal. A Pesq.D estuda em sua dissertação corporalidade, identidade, ballet e companhias de dança, sendo que se aprofundou em textos que tivessem intersecções com essas temáticas. A Pesq.M, em um trabalho seu sobre o engajamento corporal de mulheres na prática pentecostal, aproximou-se de textos que buscassem construir uma interseção entre os temas da religião, do gênero e da corporalidade. Desse modo, mesmo que tradicionalmente estudadas a partir de um paradigma abstrato-representacional-mental - rituais, identidade, religião, gênero - diferentes teorias poderão ser utilizadas no sentido de auxiliar os pesquisadores no processo de reflexão, análise, reconstrução das corporalidades de seu campo empírico. A Pesq.S reflete sobre essa ideia ao dizer que, quando utilizamos a filosofia da corporalidade, "não é que nós vemos uma problemática nova, seguimos vendo relações de poder, seguimos vendo conflitos, cooperação, vendo os mesmos problemas que analisaríamos através do discurso, mas agora nos os vemos atuando na prática".

Uma segunda atividade do momento Análise do material empírico que se apresenta aos pesquisadores das corporalidades é sua recontextualização. Aqui, repetimos a ideia de que o prefixo re se coloca a partir de uma situação no qual o contexto de pesquisa foi vivenciado em um momento anterior (vivência do campo) e, nessa fase de reflexão, resta o esforço do pesquisador no sentido de recontextualizar, ou seja, refletir sobre o contexto no qual as corporalidades ocorreram e, a partir daí, constituir uma análise das corporalidades e não apenas uma análise de movimentos corporais.

Considerando que as práticas (corporais) são mobilizadas, segundo a Pesq.M, a partir de certos eventos, ou, utilizando o termo da Pesq.D, a partir de determinado contexto, torna-se importante levantarmos que evento ou contexto é esse para melhor compreendermos tais corporalidades. Pesq.D, por exemplo, fala que para compreendermos uma postura curvada de um bailarino, devemos entender o contexto no qual essa postura ocorre, tanto o contexto mais específico do campo - Ocorreu após o término da coreografia? Ocorreu depois de uma determinada ação corporativa? - quanto um contexto sócio-histórico-cultural mais amplo - Qual é a história do ballet? Quais valores socioculturais impregnam a postura curvada? De acordo com a Pesq.D, os pesquisadores devem levar "em consideração a vivência das pessoas no mundo e a partir disso analisar seus movimentos" o que, na observação final da pesquisadora "é diferente de analisar o movimento por si só, sem levar em consideração seu contexto cultural". 
Uma situação de análise vivenciada pela Pesq.T também nos ajuda a compreender essa recontextualização da corporalidade. Quando lia seu diário de campo sobre o ritual organizacional, buscando a dimensão da corporalidade, Pesq.T percebeu três vivências corporais dos entrevistados que poderiam ser recontextualizadas: o apontar e sacudir o dedo indicador, o aumento e a imposição de determinado tom de voz, o 'inflar' e o 'murchar' dos corpos. A Pesq.T relaciona essas posturas a um contexto de uma sociedade e uma organização autoritária, autoridade essa que acaba por ser corporalizada pelos próprios funcionários que a ela estão subordinados. Essa ideia de relacionar a corporalidade ao contexto também é comentada pela Pesq.S quando diz que é muito importante, quando ela aborda qualquer realidade social a partir da corporalidade: não apenas estar presente com os corpos (o tempo da observação sensível), como também analisar "como esses corpos chegaram a ser o que hoje são", ou seja, entender a genealogia dessas corporalidades.

O processo de reflexão sobre a experiência de um campo de pesquisa fundado na corporalidade parece acionar, portanto, dois desafios que se ligam ao momento-chave análise do material empírico:

- Desafio 8 - A reconstrução das corporalidades: Se refere ao processo de elaborar uma reconstrução das corporalidades sendo que para isso o pesquisador deve se valer de uma compreensão prévia da filosofia corporalidade no sentido de poder 'capturar' e nomear as corporalidades de seu campo empírico, transformando-as em uma análise teórica que se materializa na forma de um texto acadêmico.

- Desafio 9 - A recontextualização das corporalidades: Remete à compreensão e pesquisa sobre o contexto no qual a corporalidade emerge, ou seja, o ambiente social, cultural e histórico que a compõe, sua genealogia. Nesse sentido um texto sobre as corporalidades não termina, por exemplo, na descrição daquilo que se está praticando corporalmente, mas sim na análise do contexto que produz tais práticas corporais. A análise dos materiais teóricos, do material empírico advindo do uso de técnicas sensíveis de pesquisa e, ainda, a consideração do contexto de pesquisa, todos esses elementos integrados, visam (re)produzir um conhecimento abstrato sobre as corporalidades pesquisadas.

\section{CONCLUSÃO}

Nosso foco, até aqui, foi explorar, discutir e mapear o desenvolvimento da dimensão metodológica dentro da filosofia da corporalidade a partir da experiência de pesquisadores que a praticam. Até o momento, são poucos os trabalhos dedicados exclusivamente a esse debate (DORNELLES DE ALMEIDA e FLORES-PEREIRA, 2013). Por isso, o resultado da pesquisa é a formulação, descrição e discussão de 9 desafios metodológicos, organizados em 3 momentos-chave da pesquisa qualitativa.

Dentro do momento-chave de planejamento da pesquisa, 3 desafios emergiram a partir de um processo de pesquisa no qual os antecedentes teórico-empíricos das pesquisadoras e suas leituras e entendimentos da epistemologia da corporalidade, são fases importantes:

- Desafio 1 - A aproximação em relação à filosofia da corporalidade.

- Desafio 2 - A compreensão teórica da filosofia da corporalidade.

- Desafio 3 - A compreensão de que a filosofia da corporalidade poderá trazer diferentes 'luzes' para a análise do material de campo.

No momento-chave da interação com o campo empírico, descrevemos quatro desafios a partir da percepção das pesquisadoras acerca da relevância da familiaridade do pesquisador com o campo empírico e do valor de desenvolverem uma sensibilidade no uso das técnicas etnográficas:

- Desafio 4 - O entendimento da proximidade do pesquisador com o campo empírico (familiaridade ou distanciamento). 
- Desafio 5 - O aprendizado prático sobre o que é realizar uma observação sensível.

- Desafio 6-O aprendizado prático sobre como construir um questionamento experiencial.

- Desafio 7 - O aprendizado prático sobre como realizar uma descrição imediata.

Ao analisarmos o momento-chave da análise do material empírico, formulamos dois desafios ligados à necessidade de transformar uma experiência corporal pré-reflexiva, em um texto reflexivo sobre as corporalidades:

- Desafio 8 - A reconstrução das corporalidades.

- Desafio 9 - O recontextualização das corporalidades.

Esperamos que a formulação, descrição e discussão desses nove desafios que contemplam questões epistemológicas, técnicas e analíticas da pesquisa acadêmica permita ao pesquisador das corporalidades refinar sua análise e produzir um tipo de conhecimento mais sensível aos aspectos experienciais da existência humana. O refinamento metodológico pela inclusão da corporalidade pode permitir uma melhor aproximação entre produção teórica e prática nesse campo de pesquisa.

Os resultados dessa pesquisa permitem aos pesquisadores em Administração aprimorarem suas pesquisas que têm como foco a corporalidade. Uma melhor sensibilidade metodológica pode ser fomentada na prática de pesquisa, permitindo o desenvolvimento de uma linha de pesquisa ainda pouco explorada nessa área: a corporalidade no trabalho e nas organizações. No entanto, os resultados da pesquisa não se limitam somente o campo da Administração. Pesquisadores das mais diversas áreas das Ciências Sociais e Humanas podem encontrar, neste artigo, subsídios para melhorar sua prática de pesquisa envolvendo a corporalidade. 


\section{REFERÊNCIAS}

ALVESSON, M. Qualitative research and theory development: mystery as method. London: Sage, 2011.

ALVESSON, M.; SKOLDBERG, K. Reflexive methodology. London: Sage, 2009.

BAHNISCH, M. Embodied work, divided labour: subjectivity and the scientific management of the body in Frederick W. Taylor's 1907 'lecture on management'. Body \& Society, v. 6, n. 1, p. 51-68, 2000.

BALL, K. Organization, surveillance and the body: toward a politics of resistance. Organization, v. 12, n. 1, p. 89-108, 2005.

BARRY, D.; HAZEN, M. A. Do you take your body to work? In: BOJE, D. M.; GEPHART JR., R. P.; THATCHENKERY, T. J. (Org.). Postmodern management and organization theory. Thousand Oaks, CA: Sage, 1996. 140-153 p.

BROWN, S. D. et al. Researching "experience": embodiment, methodology, process. Theory \& Psychology, v. 21, n. 4, p. 493-515, 2011.

BURRELL, G. Sex and organizational analysis. Organization Studies, v. 5, n. 2, p. 97-118, 1984.

CITRO, S. De las representaciones a las prácticas: la corporalidad en la vida cotidiana. Acta Americana: Revista de la Sociedad Sueca de Americanistas, v. 10, n. 1, p. 93-112, 2002.

CITRO, S. Memories of the "old aboriginal dances": the Toba and Mocoví performances in the Argentine chaco. The Journal of Latin American and Caribbean Anthropology, v. 15, n. 2, p. 363-386, 2010.

CITRO, S. La eficacia ritual de las performances en y desde los cuerpos. Ilha, v. 13, n. 1, p. 61-93, 2011.

CITRO, S. Ritual transgression and grotesque realism in 1990s rock music: an ethnographer among the Bersuit. In: SEMÁN, P.; VILA, P. (Eds.). Youth identities and Argentine popular music. Beyond Tango. Nova York: Palgrave Macmillan, 2012. 19-39 p.

CROSSLEY, N. Merleau-Ponty, the elusive body and carnal sociology. Body \& Society, v. 1, n. 1, p. 43-63, 1995.

CSORDAS, T. J. Embodiment as a paradigm for anthropology. Ethos, v. 18, p. $5-47,1988$.

CSORDAS, T. J. Embodiment and cultural phenomenology. In: WEISS G.; HABER H. F. (Org.). Perspectives on embodiment: the intersections of nature and culture. New York: Routledge, 1999. p. 143-162.

CSORDAS, T. J. Corpo, significado, cura. Porto Alegre: Ed. UFRGS, 2008.

DALE, K. Anatomising embodiment and organisation theory. Basingstoke: Palgrave, 2001.

DALE, K. Building a social materiality: spatial and embodied politics in organizational control. Organization, v. 12, n. 5, p. 649-678, 2005.

DALE, K.; BURRELL, G. Being occupied: an embodied re-reading of organizational 'wellness'. Organization, v. 21, n. 2, p. 159-177, 2013.

DENZIN, N. K.; LINCOLN, Y. S. The discipline and practice of qualitative research. In: DENZIN, N. K.; LINCOLN, Y. S. (Org.). Handbook of qualitative research. Thousand Oaks, CA: Sage, 2000. 1-19 p.
DORNELLES DE ALMEIDA, D. Identidade física, pessoal, institucional e espiritual: etnografia embodied de uma companhia de ballet. 168 f. Dissertação (Mestrado em Administração e Negócios) - Pontifícia Universidade Católica do Rio Grande do Sul, Porto Alegre, 2012.

DORNELLES DE ALMEIDA, D.; FLORES-PEREIRA, M. T. As corporalidades do trabalho: entre a exigência extrema e o dançar com a alma. Revista de Administração Contemporânea, v. 17, n. 6, p. 720-738, 2013.

DOUGLAS, M. Pureza e perigo. São Paulo: Perspectiva, 1966.

ECCEL, C. S.; GRISCI, C. L. I.; TONON, L. Representações do corpo em uma revista de negócios. Psicologia \& Socidedade, v. 22, n. 2, p. 309-317, 2010.

FIGUEIREDO, M. D.; IPIRANGA, A. S. R. How can we define mastery? Reflections on learning, embodiment and professional identity. Brazilian Administration Review, v. 12, n. 4, p. 348-364, 2015.

FLORES-PEREIRA, M. T. Cultura organizacional, corpo artefato e embodiment: etnografia em uma livraria de shopping center. 206 f. Tese (Doutorado em Administração) - Escola de Administração, Universidade Federal do Rio Grande do Sul, Porto Alegre, 2007.

FLORES-PEREIRA, M. T. Corpo, pessoa e organizações. Organizações \& Sociedade, v. 17, n. 54. p. 417-438, 2010.

FLORES-PEREIRA, M. T.; CAVEDON, N.; DAVEL, E. Explorando a dinâmica dos artefatos: a simbologia do corpo humano nas organizações. In: CARRIERI, A. P.; SARAIVA, L. A. S. S. (Org.). Simbolismo organizacional no Brasil. São Paulo: Atlas, 2007.

FLORES-PEREIRA, M. T.; DAVEL, E.; CAVEDON, N. Drinking beer and understanding organizational culture embodiment. Human Relations, v. 61, n. 7, p. $1007-1026,2008$.

GEERTZ, C. Obras e vidas: o antropólogo como autor. Rio de Janeiro: Ed. UFRJ, 2005.

GERGEN, M. M.; GERGEN, K. J. Qualitative inquiry: tensions and transformations. In: DENZIN, N. K.; LINCOLN, Y. S. (Org.). Handbook of qualitative research. Thousand Oaks, CA: Sage, 2000. p. 1025-1047.

GUBRIUM, J. F.; HOLSTEIN, J. A. The new language of qualitative method. New York: Oxford University Press, 1997.

HASSARD, J.; HOLLIDAY, R.; WILLMOTT, H. (Org.). Body and organization. London: Sage, 2000.

HINDMARSH, J.; PILNICK, A. Knowing bodies at work: embodiment and ephemeral teamwork in anaesthesia. Organization Studies, v. 28, n. 9, p. 1395-1416, 2007.

HOLLIDAY, R.; THOMPSON, G. A body of work. In: HOLLIDAY, R.; HASSARD, J. (Org.). Contested bodies. New York: Routledge, 2001. p. 117-133.

KERFOOT, D.; KNIGHTS, D. The best is yet to come? The quest for embodiment in managerial work. In: COLLINSON, D. L.; HEARN, J. (Org.). Men as managers, managers as men. London: Sage, 1996. 78-98 $p$. 
LE BRETON, D. Antropología del cuerpo y modernidad. Buenos Aires: Nueva Visión, 2002a.

LE BRETON, D. La sociología del cuerpo. Buenos Aires: Nueva Visión, 2002b.

MATOS, O. O corpo e o poder. Revista de Administração de Empresas, v. 24, n. 1, p. 42-44, 1984.

MAUSS, M. Sociologia e antropologia. São Paulo: Cosac \& Naify, 2003.

MERLEAU-PONTY, M. Conversas: 1948. São Paulo: Martins Fontes, 2004

MERLEAU-PONTY, M. Phenomenology of perception. New York: Routledge, 2005.

MONAGHAN, L. F. Embodying gender, work and organization: solidarity, cool loyalties and contested hierarchy in a masculinist occupation. Gender, Work and Organization, v. 9, n. 5, p. 504-536, 2002.

PRASAD, A.; PRASAD. P. The coming age of interpretative organizational research. Organizational Research Methods, v. 5, n. 4, p. 4-11, 2002

RABELO, M. C.; ALVES, P. C. Corpo, experiência e cultura. In: ENCONTRO ANUAL DA ANPOCS, 25; 2001, Caxambu. Anais... Caxambu, MG: ANPOCS, 2001.

RABELO, M. C.; MOTA, S. R.; ALMEIDA, C. R. Cultivating the senses and giving in to the sacred: notes on body and experience among pentecostal women in Salvador, Brazil. Journal of Contemporary Religion, v. 24, n. 1, p. 1-18, 2009.
RABELO, M. C.; SOUZA, I. Temporality and experience: on the meaning of nervoso in the trajectory of urban working-class women in Northeast Brazil. Ethnography, v. 4, n. 3, p. 333-361, 2003.

ROSA, A. R.; BRITO, M. J. "Corpo e alma" nas organizações: um estudo sobre dominação e construção social dos corpos na organização militar. Revista de Administração Contemporânea, v. 14, n. 2, p. 194-211, 2010.

SCHEPER-HUGHES, N.; LOCK, M. The mindful body: a prolegomenon to future work in medical anthropology. Medical Anthropology Quarterly, v. 1, n. 1, p. 6-41, 1987.

SHILLING, C. The body and social theory. London: SAGE, 2003.

SINCLAIR, A. Body and management pedagogy. Gender, Work and Organization, v. 12, n. 1, p. 89-104, 2005.

SOUZA, E. M.; COSTA, A. S. M.; PEREIRA, S. J. N. A organização (in) corporada: ontologia organizacional, poder e corpo em evidência. Cad. EBAPE.BR, v. 13, n. 4, p. 727-742, 2015.

STYHRE, A. The (re)embodied organization: four perspectives on the body in organizations. Human Resource Development International, v. 7, n. 1, p. 101-116, 2004.

TRETHEWEY, A. Disciplined bodies: women's embodied identities at work. Organization Studies, v. 20, n. 3, p. 423-450, 1999.

VÍCTORA, C. G. Inside the mother's body: pregnancy and the 'emic' organ 'the body's mother'. In: LEIBING, A. (Org.). The medical anthropologies in Brazil. Berlin: VWB, Verlag für Wissenschaft und Bildung, 1997. v. 12. 169-175 p.

Maria Tereza Flores-Pereira

Doutora em Administração pela Universidade Federal do Rio Grande do Sul (UFRGS); Professora Adjunta na Escola de Administração da UFRGS, Porto Alegre, RS, Brasil. E-mail: mtfpereira@terra.com.br

Eduardo Davel

Ph.D. em Administração pela École des Hautes Études Commerciales de Montreal (Canadá); Professor Adjunto na Escola de Administração da Universidade Federal da Bahia (UFBA), Salvador, BA, Brasil; Pesquisador do CIAGS - Centro Interdisciplinar de Desenvolvimento e Gestão Social (UFBA); Editor da RIGS - Revista Interdisciplinar de Gestão Social. E-mail: davel.eduardo@gmail.com

Dóris Dornelles de Almeida

Doutoranda em Dança pela University of Roehampton (London, U.K.); Professora Associada do Curso Dança, Departamento de Artes e Humanidades, da Universidade Federal de Viçosa (UFV), Viçosa, Minas Gerais, Brasil. Email: doris.dornelles@ufv.br 